\title{
COMMENTARY ON THE LIMITS OF COMPENSATION AND DETERRENCE IN LEGALREMEDIES
}

\author{
WILLIAM T. A LLEN*
}

\section{INTRODUCTION}

The subject of this symposium, corporate misconduct and the legal system's potential to deter it, is a matter of substantial importance. R egularly, if not daily, print and broadcast journalists report violations of legal norms by business corporations that affect thousands of persons. If the savings and loan industry debacle was the most painful example of widespread business misconduct that caused public as well as private injury, ${ }^{1}$ the emerging healthcare industry problems with illegal side payments to physicians appear to be the most recent. ${ }^{2}$ Problems of systematic corporate violation of legal norms have public significance in large part because of the scale of the operations of the modern publicly financed corporation. Much of our economic production occurs within the corporate form of organization. We are naturally concerned that legal rules designed to protect private rights and public health, safety, and welfare be observed as these organizations function to produce wealth. Thus, it seems quite natural for us to consider the deterrence effects that our system of rules and remedies create. A s this issue of $L$ aw and Contemporary Problems demonstrates, the deterrence of rule violations is, however, not entirely simple.

I welcome the invitation to comment upon the scholarly papers of Professors J ames Cox and D eborah D eM ott. ${ }^{3}$ Their thoughtful articles richly reward the attention of their readers. B ut before I make any comment directed specifically to those papers, I first offer some more general comments on the topic of deterrence.

Q uestions raised by the subject of appropriate deterrence of corporate misconduct may sensibly be sorted into two broad classes. The first class of ques-

\footnotetext{
Copyright (c) 1997 by L aw and Contemporary Problems

This article is also available at http://www.law.duke.edu/journals/lcp.

* Professor of Law, New Y ork U niversity; Professor of Business, L eonard N. Stern School of Business; D irector, NYU Center of Law \& Business; Chancellor, Court of Chancery of the State of D elaware, 1985-97.

1. See, e.g., $S \& L$ M ess, The $E$ nd is $N$ ear. A t L ast. M aybe., TIME, M ar. 29, 1993, at 15.

2. See, e.g., Jill Smolowe, H ealthy, Wealthy and Fraudulent, TIME, A ug. 30, 1993, at 24; The M edicare Grifters, TIME, J uly 13, 1992, at 20.

3. James D. Cox, Private Litigation and the Deterrence of Corporate Misconduct, $60 \mathrm{LAW} \&$ CONTEMP. PROBS. 1 (A utumn 1997); D eborah A. DeM ott, O rganizational Incentives to Care A bout the L aW, 60 LAW \& CONTEMP.PROBS. 39 (A utumn 1997).
} 
tions is not restricted to corporate behavior but deals with deterrence by the legal system of rule violations generally. Included in this branch of our inquiry would be such general questions as why we believe, if we do, that deterrence of rule violation is a social good; how do we know what steps are appropriate to achieve deterrence; and, most fundamentally, how do we determine what, with respect to every rule we seek to enforce, is our deterrence objective? In other words, the questions focus on what constitutes optimal deterrence?

The second class of issues focuses on the unique aspects of the deterrence problem when we seek to deter not a human actor but a complex firm. Q uestions falling within this class interest us for reasons both of practicality and of theory. They are practically important because a dominant part of our productive assets and our economic activity occurs within the corporate form. Therefore, because we seek to have these organizations advance rather than retard public efforts to regulate human health, safety, and welfare, we seek to deter their violation of legal rules.

The corporate form, like any complex organization, raises special questions when we ask about deterrence of rule violations. Those special questions arise from the presence of the so-called agency problem within the firm: That is, the effects of having information and control over corporate property and processes in the hands of persons whose economic interests in the enterprise diverge to some extent from those of the residual claimants to the firm's revenue, its shareholders. The issues that fall within this class of inquiry include basic questions such as why we should seek to deter corporations instead of, or in addition to, trying to deter the human actors who violate rules. In other words, why do we have vicarious liability? If we seek to affect corporate conduct through corporate level sanctions for rule violation, what legal test ought we employ to determine when a corporation will be liable for the acts of its agents?

The contributions of Professors Cox and D eM ott fall within the second and more strictly legal institutional class of questions. In commenting briefly on the subject of deterring corporate misconduct, I want, however, to begin with the first class of more general questions, most centrally what could we mean by optimal deterrence. This is because I believe that the concept of optimal deterrence should provide the essential backdrop for our thinking about deterrence policy in our law. Thus, it is important to try to define and apply it notwithstanding the very substantial difficulty that task entails. The second part of my comments will deal more specifically with the interesting contributions of Professors Cox and D eM ott.

II

\section{DeterRENCE IN A LEGAL SYSTEM}

O ur legal system performs a large number of functions. A t a very high level of generalization, we might characterize those functions as falling within four general areas. First, the legal system provides a method to determine the 
authenticity or authority of statements that purport to constitute legal rules. ${ }^{4}$ This function authorizes the process of the positive creation of legal rules or codes, and establishes standards for authenticating positive legal rules of all sorts. Second, the legal system facilitates social interaction and economic production by defining rights and establishing procedures by which people can voluntarily create rights and duties and affect legal status. Thus, for example, the law defines the acts necessary to constitute a valid will, a valid contract, a valid marriage, or a valid transfer of property rights. Third, the legal system enforces legal duties through criminal and civil processes, fixing and enforcing compensation for some losses caused by violations of legal duties and prosecuting and punishing violators of criminal law. Fourth, in authoritatively announcing and enforcing legal norms, the legal system contributes to the construction of a social identity of the people who identify with it (or commit their allegiance to it), thus tending to shape their behavior non-coercively.

D eterrence is one aspect of the enforcement function of the legal system. To the extent that rules and remedies can be formulated in a way that accomplishes optimal deterrence, the more costly means of ex post enforcement of rules can be avoided.

\section{A. O ptimal D eterrence}

A concept of optimal deterrence is central to our intelligent design of remedies for violations of legal duties. B ut how do we fashion such a concept? When we ask what our concept of optimal deterrence is, we are, in effect, asking about our ideal of legal compliance. If our ideal world is one in which all legal rules are always voluntarily obeyed, then we have implicitly adopted a concept of optimal deterrence as that level of deterrence that causes all legal obligations to be voluntarily respected.

To demonstrate that we ought not aspire to deter all rule violations, think about the highly useful rule that provides that contracts validly made should not be intentionally breached. A s a hypothetical, consider now that, in some other legal world, the remedy for intentional failure or refusal to perform such a contract is capital punishment. E ven though the example strikes one as absurd, it is instructive. The substantive rule is certainly a good rule. It promotes the general welfare by facilitating contracting, reliance, and economic activity of all sorts. A nd the remedy, if effectively enforced, would almost certainly deter intentional breaches of contract. It is intuitively apparent, however, that such a strict policy of deterring intentional breaches of contract is too much of a good thing. But why? I suppose that we intuit that the remedy over-deters in this instance because, first and foremost, we feel that the remedy lacks proportionality. While we want contracts to be performed we are not willing to insist on such performance at the cost of human life. We value some things more than the (large) marginal contribution to human welfare that enforcing con-

4. This logically essential feature of a legal system was aptly called the "R ule of R ecognition" by H.L.A. Hart. Seeherbert L.A.HART, The CONCEPT Of LA W (1994). 
tracts provides. Secondly, I think we intuit that even if human life were not involved (substitute the forfeiture of all of the promisor's property for the death penalty in the hypothetical), there still will be contract performances that we do not want to coerce to this extent. If the promisor will lose more from performing his contract than the promisee will gain from it, why should the legal system enforce this loss? The alternative technique of fully compensating the promisee for his losses, including his expected profit on the transaction, if feasible, seems intuitively superior. ${ }^{5}$ In other words, one ought not want to deter this violation, only compensate for losses it occasions.

\section{B. Human W elfare $G$ oal of $L$ aw}

If strict obedience to legal duty is not the highest value of the legal system, what is? In the context of thinking about remedies, what is the standard to which legal actors-policy makers, administrators, and judges-should look to conceive of optimal deterrence? A ny such ultimate value will, of course, have to be expressed in a broad generalization. O ne may defensibly think of justice as the ultimate legal system value. A concept of justice that would serve this purpose necessarily would extend beyond compliance with law. It would include concepts of social justice, since the ultimate ends for which we organize our society are to some extent exogenous to the legal system. The working out of what justice was thought to require would constitute an ongoing community self-reflection.

But justice seems to me a less useful description of the legal system's ultimate aim than an alternative: the advancement of human welfare. This concept is, of course, no more objective than is justice, and agreement on its meaning too could only be achieved through an ongoing social construction process. B ut human welfare seems to me a superior characterization of the major goal of our legal system. It can incorporate the requirements of social justice, with a recognition of the important role that production of material goods can have on the welfare of the population.

W hat constitutes human welfare is, of course, itself debatable. We need not enter that debate now. It is enough to acknowledge the multifariousness of the human welfare goal and to observe that obedience to rules of law is not the whole of it. Thus, legal rules fashioned to address a particular context are often adjusted when they are deployed in contexts in which values other than the one that the rule sought to protect become implicated.

In our effort to reason about deterrence of legal wrongs, we can deploy the concept of advancement of human welfare. I suggest as a working concept the following: O ptimal deterrence is that set of circumstances (substantive rules, procedural devices, and legal system practices) that creates the best set of incentives for all citizens to act in ways that advance the general welfare. The

5. The intuition is, of course, premised on the idea that more wealth is socially preferable to less wealth. With greater wealth, governmental redistributional schemes allow for the relief of more human suffering and the advancement of various aspects of human welfare. 
question thus becomes how do we know when the general welfare is advanced by permitting a rule violation to occur (that is, by sanctioning it in a way that rationally permits it to occur, as in our earlier efficient breach hypothetical)? In making this determination, a fundamental distinction could be drawn between breaches that affect only personal property interests or expectations and those that affect public interests, which may be more difficult to value.

\section{Public W rongs and Private W rongs}

In considering general legal system deterrence, and particularly deterrence of corporate misconduct, it is helpful to divide legal rules, somewhat artificially, into those protecting private interests and those protecting public interests. If we at first limit our inquiry to the enforcement of rules that advance the general welfare through facilitation of private activity-such as rules enforcing contracts, or protecting property interests-we find, I think, a rather plausible proxy for the advancement of human welfare in the compensation concept and the damage remedy. Of course, trying to value losses in monetary terms may be problematic. The obvious example is pain and suffering. But the valuation problem is inherent in any attempt to advance multiple values. In cases in which rules designed to protect commercial interests are involved, however, the market measure of value is certainly dependable. In that context, the compensation remedy has a strong claim to advance the general welfare. It does this by permitting a socially beneficial breach to occur while fully compensating the party to whom the legal duty was owed. ${ }^{6}$

Thus, the garden variety remedy for violation of legal rights protecting a private interest-monetary compensation for the amount of the loss proximately caused by the breach of duty-is not only capable of a substantial deterrent effect, but where there are no public costs associated with the breach, it does so in an appropriately tailored way. The award of appropriate compensatory damages in a private wrong has two signaling effects. First, it signals to strangers to the action that their own future violations of the rights of others will result in their being forced to pay appropriate compensation. Second, it signals that if the violation is itself value producing, the law will not foreclose the realization of that net value.

What is notable about this inevitable deterrent effect of money damages is that, in a world of perfect information and no transaction costs, it would approach our concept of optimal deterrence. In order for the compensatory remedy to constitute optimal deterrence, the following conditions would be required. First, it would be necessary that all costs associated with the breach of duty are incurred by the parties to the suit. Second, a court or other agency would have to be able to price correctly the losses arising from the breach, including the time value of money. Third, the breaching party would have to be

6. See generally 3 E. A LLA N FARNSWORTH, FARNSWORTH ON CONTRACTS $\S 12.3$ (1990). 
solvent and believe, at the time of the breach, it is capable of paying full damages.

Each of these conditions of an optimal compensation deterrent effect are, of course, problematic in fact. U npriced effects on others do frequently occur even in apparently private suits. Full compensation of all injured parties is also problematic. Limited information and human cognition mean that courts will not always appropriately weigh the costs of a breach. The Texaco v. Pennzoil ${ }^{7}$ case, with its breathtaking award of compensatory and punitive damages, was only an astounding example, not a unique one, of the erratic quality of damage awards. Moreover, transaction costs of adjudication will rationally foreclose some claims from being asserted at all. Finally, while those costs will fall on both sides of a dispute, the defendant who has breached a duty may impose uncompensated losses on the plaintiff by reason of the fact that the legal rate of interest may be less than plaintiff's cost of debt. If the interest rate is less than defendant's cost of debt, the defendant will have an incentive to impose this cost on the plaintiff. In that event, the defendant will have a financial incentive to delay the process of adjudication and the payment of the judgment.

Thus significant problems in the administration of the legal system mean that the compensation remedy itself will fail to achieve optimal deterrence.

\section{Correcting U nder-D eterrence}

Where corporate violators are involved, the most notable source of imperfections in the deterrent effect of the compensation remedy arises from the collective action problems that occur in mass torts or other class injuries. These problems are not a logical consequence of the corporate form, but are associated with the practical fact that mass torts arise most often from commercial activities conducted in the corporate form. The collective action problem is the familiar one: A breach of a duty owed to a large class of people may result in substantial collective loss but a loss to each class member that is too modest to justify incurring the costs associated with establishing each injured person's right to compensation. Logically related to this problem is the problem of the low visibility breach-that is, a breach of duty that is not easily detected. In this circumstance, a rational defendant might calculate the benefits of breach and weigh them against the present value of the probable amount of any compensation award discounted by the probability of discovery. There is no social gain in a breach that benefits the breaching party only because he will not have to pay full damages. Such a breach is inefficient (that is, making all of the same assumptions about the absence of an effect on the public and the ability of prices to reflect value accurately). B oth of these situations-small individual class claims and low visibility claims-represent important instances in which the compensation remedy will under-deter wrongs.

7. Texaco, Inc. v. Pennzoil Co., 729 S.W.2d 768 (Tex. Civ. A pp. 1989). 


\section{E. Class-based R emedies}

Two legal system institutions arguably help to move compensation toward optimum deterrence: the class action and the institution of punitive damages. E ach, however, is a very imperfect means to move toward optimal deterrence. The wide-spread adoption of the 1966 federal amendments to the class action rule presents the most obvious and important example of a legal innovation that has the effect of making the compensatory remedy a more effective deterrent. It does this by facilitating the inexpensive joinder of small claims, under established circumstances, so as to make the adjudication of related claims of breach of duty by a single defendant (or a set of defendants) economically feasible. A s it becomes more feasible for classes of injured persons to seek judicial redress, the incentive to infringe rights is reduced. Thus, the class action is the preeminent innovation allowing the compensatory goal to serve the deterrent function more effectively.

A s is well understood, however, the class action suit itself suffers from substantial agency problems that are only partly mediated by the judicial supervisory role in such suits. ${ }^{8}$ A cademic commentary is one thing, but concern about the problems of shareholder litigation go far wider than those academics expert in the economic analysis of group action. D iscussion is widespread in the press and in legislatures of the agency problems of suits controlled not by the holders of legal rights but by lawyers who will seek a fee typically thousands of times larger than the award a class member may receive. Of course, such discussion is irksome to members of the plaintiffs' class action bar who regard themselves, generally with reason, as principled and professional. Nevertheless, it seems clear that the agency problems that arise in class actions limit the ability of such suits to bring the compensatory function of civil litigation into alignment with the deterrent aim of the law. Thus, an important question for improvement of our systematic ability to achieve natural deterrence is whether there are changes in the class action mechanism that may reduce agency costs of the suit. Such changes could, of course, involve a large number of matters from the simple expedient of solving the collective action problem by auctioning the claim to a single person or entity as Professors M acey \& M iller have suggested, to modifying pleading standards and settlement procedures. Professor Coffee has what he calls a "bill of rights" for class members, including elections of representation. ${ }^{9}$

8. See J ohn C. Coffee, J r., Understanding the Plaintiff's A ttorney: The Implications of E conomic Theory for the Private $E$ nforcement of $L$ aw Through Class and D erivative A ctions, 86 COLUM. L. REV . 669, 677-84 (1986); J onathan R. M acey \& G eoffrey P. M iller, The Plaintiff's A ttorney's R ole in Class A ctions and Derivative L itigation: E conomic A nalysis and Recommendations for R eform, $58 \mathrm{U}$. CHI. L. REV . 1, 19-28 (1991).

9. See J ohn C. Coffee, Testimony B efore Senate Subcommittee on A dministrative O versight of the Courts, 1997 WL 683686, at *16 (O ct. 30, 1997). 


\section{F. Punitive D amages}

A s important as class suits may be in trying to align damages with total loss caused by the breach by aggregating the loss, they cannot optimally deter. Consider the low-visibility breach. In the low-visibility breach, one who owes a legal duty may be induced to violate the duty because there is a material chance the breach will go undetected. Substitution of lower cost ingredients in a product or arranging for the payment of fiduciary funds in a way that gives to the payor an extended use of the funds might constitute breaches that have a low probability of detection. ${ }^{10} \mathrm{~A}$ rational defendant may be tempted to engage in low-visibility breaches (especially if he or she is rationally unconcerned about repeat business) because, if compensation is the sole remedy, the present value of the breach will be (absent consideration of costs of suit) greater than the present value of a probable judgment.

Punitive damages are one way in which a defendant may be deprived of expected gains from a breach in a low-visibility breach context, thus deterring breaches. Consideration of the deterrent impacts of punitive damages is illuminating both in its similarities and its differences to the effects of the class action device. Punitive damages are not compensatory; they serve a deterrence and a pedagogic function. Rationally, the prospect of punitive damages will cause rational calculating actors to adjust upwardly the expected value of judgment against himself and thus to reduce the net present value of the proposed breach. From a pedagogic perspective, punitive damages powerfully announce a community standard, and, by affixing a greater or smaller penalty for its breach, they attempt to attribute some relative weight or importance to the manner of its violation.

A s all pedagogic functions of law, punitive damages have a utilitarian and a non-utilitarian aspect. In its utilitarian aspect, punitive damages can have the effect, like class action judgments, of moving a damage award toward a theoretically optimum level that would deter rational violators. Punitive damages seem superior to the class action with respect to deterrence in one respect: Punitive damages, since they are for all practical purposes without an upper limit, ${ }^{11}$ are capable of removing from the breaching party the prospect of any profit from the breach, and of visiting upon the breaching party a substantial loss arising from the breach. In principle, the strictly compensatory class action is not capable of this result. ${ }^{12}$

But what is particularly notable about punitive damages is not simply the ability of the device to deter, but also the unpredictability of its deployment by juries. In charging juries to consider the appropriateness of an award of puni-

10. See, e.g., G oodrich v. E.F. H utton G roup, Inc., 681 A .2d 1039, 1041-42 (D el. Sup. Ct. 1996).

11. But see BM W of N. A merica, Inc. v. Gore, 116 S.Ct. 1589 (1996) (holding that there is some constitutional protection against grossly excessive punitive damages). See generally Developments in the L aw - J ury D etermination of Punitive D amages, 110 H A R V. L. R E V . 1513 (1997).

12. In fact, however, the calculation of compensatory damages in large class actions would be such a complex and difficult process that the practical effect of the prospect of such an award might not be so different from the effect of the threat of open-ended punitive damages. 
tive damages, courts do not attempt to guide them into some calculation designed to estimate the amount that would be appropriate to deter such conduct. $R$ ather, courts allow juries, as the delegated voice and conscience of the community, to make a direct expression of its reaction to the conduct of the defendant. How that judgment gets converted into dollars is largely an unexamined and unguided process. ${ }^{13}$

While punitive damages are capable of correcting for systematic underdeterrence, they do not do so optimally. They are capable of over-deterring. If a rational or efficient breach entails some risk of an unknowable but large additional payment occasioned by the jury's reaction to the breach, the number of welfare-enhancing breaches of duty will decrease.

\section{G. O ptimal D eterrence of Invasions of Public Interests}

Questions of optimal deterrence are even more complex when rights that protect public interests are implicated. The problem of defining optimal deterrence remains the same; what is more difficult is affixing a value to the interests that are impacted by the violation of duty. Where public regulation of health, safety, and welfare are involved, the question of "efficient breach" is more difficult since information concerning the effects of the breach will be hard to estimate either ex ante by the rule formulator or ex post by the enforcement agency or court. That does not mean that in this setting optimal deterrence is a condition in which no violations occur. It remains the case that complex human welfare is the goal we should seek to advance and not blind obedience to an ex ante pronouncement.

Consider an example of public regulatory deterrence, the regulation of air pollution. Let us consider the matter at the point that the regulator had formulated a standard. Once the rule formulator has fixed a standard for acceptable and unacceptable levels of a particular form of air pollution, that standard must be observed by the regulated firms and enforced by the public agency (or perhaps by "private attorneys general"). The standard with which we wish people to comply should of course be stated as precisely as circumstances permit. N evertheless, compliance with the standard will usually involve judgments of probabilities that depend on a host of technological, environmental, or market variables. So while we would expect the air pollution standards to be expressed in some measurable terms-for example, parts per million of identified impurities released into the air-compliance with the standard will inescapably involve judgment. Technological control mechanisms available to govern the emission process under varying environmental conditions

13. SeeEdWARD J. DEVItT ET AL., FEDERAL JURY PRA CTICE AND INSTRUCTIONS § 86.09 (1987) (M odel charge for punitive damages: "If you find that the acts of defendant were willful, wanton, and maliciously done, then you may add to the actual amount of damages such amount as you shall agree is proper. The purpose of punitive damages is not to compensate plaintiffs, but to punish the defendant and to deter defendant and others from committing such acts in the future."). 
may be more or less imperfect and that fact will necessity judgments concerning safety margins.

Designing a production process that will both advance the corporation's economic mission and assure compliance with the law will be problematic because of information and technology imperfections. Legal compliance, while advancing the corporate purpose, will logically entail corporate agents making a probabilistic assessment of the chances that any given set of production inputs will give rise to some violation of the announced standard with some degree of frequency. Consideration of the probabilities that a particular production plan may cause a violation of the standard and how often that violation may occur will be an inevitable part of the production planning process. The probability of violating the standard can be reduced by adopting a set of production inputs that stay very far away from inputs that would be optimizing from the point of view of the firm if it were able to impose environmental damage without incurring costs. Such a strategy-wide margins of safety-may satisfy the corporation's duty not to violate the standard, but it will not optimally advance human welfare, since it will preclude some level of production that might have safely been extracted from the system. L egally, the duty that this strategy will stress is the director's duty to the corporation and its shareholders. Management does, of course, have a legal duty to advance the long-term financial interests of the corporation and its shareholders. It may not be an available option, both as a matter of legal duty and also as a matter of market competition, simply to set the production process inputs at a level at which there is essentially no risk of possible violation.

In principle, both the duty of legal compliance and of loyalty to the longterm financial interests of the investor may each be satisfied where information is available that permits the corporation to price the cost to the corporation of its occasional violations of the standard. In a world of complete information of this type, the government would express the relative importance of compliance by setting the price or penalty in advance for various types and frequencies of violations. Such information would permit persons rationally to comply with the standard in a way that is consistent with achievement of other human welfare-enhancing goals. The higher the price or penalty occasioned by the violation, the more care management will take to avoid that cost. With such information, management could calculate the profit from the transactions that risk violation of the standard and weigh them against the fine that such conduct would engender if the violation occurred (discounted, of course, by the risk of violation). M anagement might have to add an estimate for other costs, if any, but this system would permit a rational calculation respecting risks that would permit the system to move toward the posited goal of optimizing human welfare.

In a world of complete information and fully effective legal mechanisms, optimal deterrence would result in the occurrence of only those breaches of duty that increase total production (measured in dollars) when the payment of fully compensatory damages are counted as a production cost. O ptimal, not 
perfect, deterrence thus understood is a worthy social goal. It would not, to any extent, demean the public interest or glorify profit-making unduly. It simply seeks increased rationality. Such a policy would place a burden on the formulator of a rule and its remedy to try, at the time of the promulgation of the rule, to provide information concerning the rule's importance.

The fundamental point is that, even in this hypothetical world of almost perfect information, violations of the standard would exist because some violations will be value enhancing. A t most levels of ex ante penalty, there will exist some set of factors affecting the corporation's decisions that would make a probability of future non-compliance (at some frequency) optimal. ${ }^{14}$ If we assume that the ex ante penalty does correctly establish a social cost for such violation of the standard, then there is a social interest in having the firm adopt that set of production inputs that will optimize the corporation's financial performance even considering the possible violation of the standard.

Thus, where the penalty is strictly monetary, rational deterrence of violations and public health, safety, and welfare regulation is possible in principle. Where criminal law violations are involved, however, matters get even more complicated. Criminal law, with its penal sanctions, cannot be (or at least are not) dealt with by corporations or their management with the same calculus as violations of civil rights. For good reason, corporate directors will not direct management to calculate the costs and benefits of compliance with criminal law. Nor will their lawyers advise them that they may safely do so. The pedagogic message of criminal sanctions is "take all necessary steps to avoid the proscribed act." Criminal remedies provide the strongest set of deterrence signals.

\section{H. Institutional Competence}

The formulation of a concept of optimal deterrence is a fundamental necessity in order rationally to analyze policy respecting deterrence of corporate or any other misconduct. The concept that I find helpful-maximization of net wealth-is not difficult in principle. A pplication of this principle, however, would be exceptionally problematic in practice. It only works well if one assumes that costs of the violation can be responsibly identified and estimated. ${ }^{15}$ Obviously, obtaining or estimating such information is problematic. But the difficulty of the task and the imperfection with which it can be done does not justify avoiding grappling with it. A ll else is intuition. Intuition is of course in-

14. Non-compliance would also exist for the independent reason that, whatever the "price" for a violation is, the probability that it will have to be paid is less than $100 \%$. Therefore, rationally acting officers may produce a less than optimum amount of compliance unless the regulators have successfully factored that fact into the establishment of the penalty or price in the first instance.

15. Where one is considering health, safety, and welfare legislation, the difficulty of that task derives from at least two problems: incomplete data with respect to the human health effects of given levels of contamination or pollution and the absence of a clear standard to convert estimated health impacts into dollars. 
evitable in the construction and operation of a legal system, but we ought to strive for rationality and turn to intuition only when driven to it.

The definition of optimal deterrence requires rich specific information. Thus a first step at thinking about construction of a legal regime that tends to create rules and procedures that approach that ideal is to ask ourselves what institutional arrangements can best produce this result. O ne possibility is, of course, that enforcement agencies, such as courts or administrative tribunals, that would be only very broadly constrained, could ex post evaluate the conduct in the context and establish an appropriate penalty for a breach of a public duty. Such ex post remedy formulation would have a potentially huge informational advantage over an agency that created a penalty ex ante. They would have better information about all of the factors surrounding the actual violation of standards. For that reason, they may be in a superior position to estimate the value of social harm occasioned by the violation. If the court could responsibly estimate the dollar value of that impact and impose it upon the defendant, and the defendant could foresee that consequence then, from a pedagogic perspective, it will appropriately signal regard for the law.

There are substantial problems with this approach, however. Most importantly, it does not make clear information available to the regulated party at the time it must choose its production inputs. Therefore, welfare-maximizing decisions could not be made ex ante. Second, a responsible estimation by a court of the costs associated with a particular violation of the Clean A ir A ct, as in our example, would be an extremely difficult and costly endeavor. While the court (or any enforcement agency) acting ex post does have, in principle, an informational advantage over the ex ante rule formulator, the court has corresponding disadvantages. First, it will have little expertise in estimating the necessary values, and speaking of courts at least, their processes are not well suited for such large-scale questions. M ore importantly, the transaction costs associated with repeated individual determinations of the social costs of violations would be large, certainly far greater than a single administrative ex ante determination.

The advantages of having the agency that formulated the rule be the agency that "prices" violations in order to deter violations optimally are powerful. Most importantly, as a legislative or administrative body, its process can be adjusted to consider a broader range of policy matters than can a court. Second, the agency's opportunity for collecting information is greater, as are its resources, and it is not constrained by its own precedent. Third, in our legal tradition, the shaping of a penalty or fine has predominantly been seen as a legislative function-not a judicial one. Fourth, the rule formulator may reverse its prior decisions with greater freedom than may a court, or indeed any other ex post enforcer. Fifth, the rule formulator can shape a fine or penalty response that considers public policy in all of its myriad aspects. 


\section{Summary R especting the Pursuit of O ptimal D eterrence in a Sub-O ptimal World}

For these reasons, I believe that, when the liability rule that we seek to enforce through appropriate deterrence protects against a private loss, we ought to provide compensatory remedies that offer a low cost means to determine damage and award compensation. The class action should be that device, but steps to moderate the agency problem inherent in its structure will have to be taken before further progress can be made with respect to its use. Punitive damages have certain advantages as a deterrent, but are in fact so imperfectly controlled under existing law and practice that, as a legal system device, it is not clear that punitive damages produce a net welfare gain or loss. The path of law improvement, in my opinion, lies in fashioning appropriate devices to narrow the circumstances in which a jury is authorized to punish in this way.

When the liability rule in question is designed to protect a public interest, the fixing of an appropriate penalty only ex post deprives the regulated parties of information sufficient to allow them to calculate what constitutes optimal (wealth maximizing) behavior for themselves and thus deprives us all of the capacity to arrange affairs in a way that optimizes human welfare (on a special but not indefensible set of assumptions that associates optimal human welfare with optimal production of total wealth (so-called $\mathrm{K}$ aldor-Hicks efficiency). Therefore it is plausible that the more likely path toward optimal deterrence in this setting is the expenditures of public resources at the outset sufficient to create a set of specific penalties. While specific penalties would necessarily be set forth in classes and thus the fines would not always perfectly match the expected cost of public injury done by the violation, such a technique would allow the regulated to understand the consequences of their acts when they planned their production inputs. In all events, it is important that our law and policy be premised on an understanding that greater deterrence is not necessarily the same thing as optimal deterrence. We need a theory to estimate optimal deterrence. Such a theory will allow us to view each substantive rule and its remedy in a larger context before making a judgment about the rule's appropriate sanction.

\section{DeterRing Corporate Rule ViOLATIONS}

With a general notion of the logical necessity and practical difficulty of the concept of optimal deterrence in mind, let us turn to Professor Cox's rewarding contribution. It weaves together several distinct strands of law and policy into an interesting engagement with the following question: How should and does the corporate law achieve a useful deterrent effect respecting corporate violations of legal duties owed to others? ${ }^{16}$ I will limit my comments to his first point, the role of vicarious liability in achieving appropriate deterrence. In that

16. See Cox, supra note 3 , at 1 . 
connection, I confess that I was not entirely persuaded by his defense of the idea that a system of strict vicarious liability is likely to be preferable to a system that has some elements of duty-based liability. ${ }^{17}$

First, I want to note a fundamental: In considering deterrence, we are only considering the calculating mind. To the extent people violate legal norms for reasons having nothing to do with calculation (for example, crimes of passion), deterrence is not an apt concept. I accept, however, that our legal system assumes that few rule violations are altogether free of every level of awareness of consequence and choice. Thus, we suppose that calculation is very often present to some, not immaterial, extent and that, therefore, deterrence is an apposite concept when considering sanction for rule violation. Thus, Professor Cox's reminder that not all misconduct is calculated as an economist might imagine is true, but not pertinent to his subject of deterrence. Generally, in human action, that which can be deterred is the subject of some process of reasoning.

Second, in analyzing the place of vicarious corporate liability in a regime of appropriate deterrence, Professor Cox accepts, but does not rely exclusively on, what I take to be a standard economic interpretation of the place of vicarious corporate liability in our scheme of rights and remedies. ${ }^{18}$ That view holds that, in a world of perfect information and fully solvent human actors, there would be no need for a regime of vicarious liability. ${ }^{19} \mathrm{H}$ uman actors would be responsible for paying full compensation from their own wealth for the injuries proximately caused by their actions in breach of a legal norm. ${ }^{20}$ Given perfect information, we would know ex ante how to sanction these wrongs so as to deter them to the optimal extent. In this hypothetical world, there is no need for vicarious liability. (Indeed, we would count upon employee "agents" constraining the acts of the corporation because the employees' own credit would be at risk!)

We, of course, do not exist in this world of perfect information and universal solvency, and it is the ways in which the real world differs from this hypothetical one that makes vicarious corporate liability sensible social policy. B ecause it is empirically the case that corporate employers are more likely to have greater assets than the individual agents they employ, the law will achieve a closer matching of risk and reward associated with the joint economic activity of the principal/agent if corporate employers/principals have control of both employee/agents and liability for agent actions done to advance the joint or corporate purposes. E mployers will therefore tend to internalize the costs attendant to the joint activity (or firm activity).

\footnotetext{
17. See id. at 2-20.

18. Seeid. at 2-8.

19. See Reiner H. Kraakman, Corporate L iability Strategies and The Cost of L egal Controls, 93 Y A LE L.J . 857, 859-69 (1984).

20. Seeid.
} 
This view accepts that the purpose of vicarious firm liability is to better match risk and reward, which will tend to produce greater allocative efficiency. B ut it leaves some important institutional questions open. Specifically, it does not specify what legal test will be used to determine whether legal liability from an act of an agent will cause liability to be shared by the firm. It is this subject that generates a certain warmth from Professor C ox.

Third, the gist of the vicarious liability portion of Cox's paper ${ }^{22}$ is a strong disagreement with the work of Professor J ennifer A rlen and Professor R einier $\mathrm{K}$ raakman concerning vicarious corporate liability. ${ }^{23}$ A ccording to Cox, Professor A rlen has observed in the current system, which is characterized largely by strict corporate liability for wrong done by employees within the scope of their duties, what she characterizes as a perverse effect. ${ }^{24}$ We are told it is this: Strict liability can create a disincentive to monitor corporate compliance with law because it has at least four possible effects. First, monitoring costs something. Thus, in a rational world, whatever the benefits are hoped to be, they must exceed the expected cost in order for monitoring to occur. Second, monitoring may decrease unlawful gains that would otherwise arise from violation of rules. The idea here is that some agent misconduct must be beneficial to joint efforts and, if agent compensation is incentive based, maybe a lot of such misconduct has benefits to the firm. Third, monitoring will raise the probability of detection of wrongdoing and thus imposition of costs (fines or damages). Fourth, monitoring may decrease exposure to adverse fines or damages because it may decrease violations. The perverse effect is the third one.

These effects cut in different directions. Logic, of course, does not dictate that the costs of monitoring plus the increased risk of fines, etc., will exceed the decreased costs of fines actually incurred. Thus, the perverse effect Professor A rlen first described does not preclude a corporation's quite sensibly undertaking monitoring and compliance programs, as Professor Cox correctly reports they are increasingly doing. But the fact that this monitoring activity may expose firms to a heightened risk of fine or damages nevertheless must logically act as an impediment to investment in monitoring. A rlen and $\mathrm{K}$ raakman observe that the risk is, by definition, magnified by a strict liability regime. ${ }^{25}$ They recommend that this perverse effect be mitigated by the law adjusting a corporation's exposure to liability where it has made a reasonable effort to inform, monitor, and correct its agents. ${ }^{26}$ Their proposed alternative would, in some respects, be a duty-based regime and, in others, a strict liability regime. ${ }^{27}$ They

\footnotetext{
21. See Cox, supra note 3, at 8-10.

22. Seeid. at 2-20.

23. For a glimpse of the A rlen-K raakman views on vicarious corporate liability, see generally J ennifer A rlen, The Potentially Perverse E ffects of Corporate Criminal Liability, 23 J. LEGAL STUD. 833 (1994); J ennifer A rlen \& R einier K raakman, Controlling Corporate M isconduct: A n A nalysis of Corporate L iability R egimes, 72 N.Y .U. L. REV . 687 (1997).

24. See Cox, supra note 3 , at 11-12.

25. See A rlen \& K raakman, supra note 23 , at $706-13$.

26. Seeid. at 735-41.

27. Seeid.
} 
approve, in many ways, the Federal O rganization Sentencing Guidelines as a composite system of a type that they would endorse, but offer several specific grounds for modifications in that approach. ${ }^{28}$

Professor Cox is disapproving of this approach. He is concerned that it would impose greater system costs by increasing uncertainty about liability standards and that it would disserve justice because when the corporation had appropriate monitor and control mechanisms in place, this standard would permit corporations to escape liability for private losses caused by the corporation's employees' violation of law. ${ }^{29} \mathrm{H}$ is critique of Professor A rlen's algebra is, in effect, a quibble. The gist of the insight remains. So long as increased risk of detection of wrongful conduct is linked to an increased risk of sanction, then, regardless of all other factors, there exists a marginal disincentive to monitor. It is not much of a criticism to say that the insight is only a model builder's insight. That is, that it cannot tell you how practically important the effect noted actually is in the world. O ne question that this observation raises is what, in the world of real events, is the marginal effect of this disincentive? O ne's intuition is that in many situations, the benefits associated with deterring organizational wrongdoing will be such as to dominate the disincentive effects, perhaps even render them trivial. Moreover, Cox is correct in pointing out that minimizing the combined costs of monitoring and sanctions is not the only reason that corporations have compliance programs. They have such programs in part because senior agents need information about the functioning of the organization to control it (either for reasons that owners are monitoring them or because they have financial and lawful incentives to do so). B ut that fact does not logically change the marginal effect of linking monitoring with the possibility of greater sanctioning, that is, the perverse effect, even though it may reduce the practical significance of the perverse incentive effect.

Professor Cox is concerned about the distribution effects of the A rlen$\mathrm{K}$ raakman approach. He foresees that the duty-based approach to corporate liability would leave uncompensated in some cases persons injured by conduct of corporate agents within their scope of employment. He cites the hypothetical case of a corporate treasurer who deliberately issues false statements in order to facilitate the corporation's getting a bank loan. U nder a duty-based system he wonders whether a buyer of the company's stock who relied on that misstatement and who was injured when the truth emerged would be able to be made whole by the corporation. If the corporation could show that it had behaved reasonably would it not be free of liability under A rlen \& K raakman's conception and is this not plainly wrong?

W ell to this writer at least, it is not so clear what is appropriate social policy with respect to this hypothetical. A t common law there would have been no corporate liability, of course, so if we intuit that that result might not be so horrific, we are not out of touch with our legal traditions. Of course, our traditions

28. Seeid. at 745-52.

29. See Cox, supra note 3 , at $12-20$. 
have evolved and it is the case that under R ule 10(b)(5) the issuer would be liable as the result of this false statement, with regard to monitoring efforts. If we are asking ourselves what is the "just" solution to this problem, my own answer would take into account (1) the increasing role of large financial intermediaries in the purchase and sale of stock, (2) the diversified nature of most stock investors (directly and indirectly), (3) the transaction (litigation) costs of the rule adopted, and (4), most importantly, the expected consequences on issuers and buyers of stock of the liability rule I formulate. Considering those factors I can only report that, if it were the conclusion that the corporation had acted appropriately in establishing and monitoring its controls, it is not obvious to me that a strict liability rule that required that the "defrauded" investors loss be compensated by the other investors (that is, the corporation) is superior to the duty alternative.

A the end of the day, Professor Cox argues that there will be greater uncertainty concerning liability standards and thus greater direct and indirect costs in the system from the substitution of the ex post duty standard than is present in the strict liability regime. For those that would advance the duty regime, those costs are clearly present but they are likely to be outweighed by flexibility in the definition of optimal deterrence that the duty-centered systems allow. A s in so very many areas of law criticism and law formulation, the answer to this dispute does not lie in concepts alone. R ational policy can be made only if we can have responsible, empirically based estimates of the costs and the benefits of each approach. This is, of course, evident but needs to be stated and restated as an encouragement to the gathering of facts.

I turn briefly to Professor DeM ott's interesting piece to make only two comments. First, this scholar gives us a very powerful insight when she reminds us just how dominating the corporate employer can be in the employeremployee relationship. ${ }^{30}$ She does well to remind us that an employer may signal an attitude toward rules even while it announces a policy in favor of strict compliance. She uses as an example Domino's Pizza delivery persons who were told to obey the traffic laws while making deliveries, while at the same time they were told that they would have to pay for any pizzas they did not deliver within thirty minutes. ${ }^{31}$ W hile this example is helpful, I am not sure that this is a strong argument supporting strict enterprise liability. In a duty-based regime, the court would be required in determining whether there was a breach of duty to determine whether the corporation had appropriately supervised the employee. That determination would not, I am certain, be limited to formal statements, but would necessarily consider all aspects of the relationship, most certainly any incentive compensation scheme. Nevertheless, consideration of this topic does begin to require one to think about what would be the level of transaction costs entailed (that is, litigation costs) were one to move from a re-

30. See D eM ott, supra note 3 , at 55-56.

31. Seeid. at $45-46$. 
gime of strict liability (within a broad agency model) to a duty or composite model.

Second, Professor D eM ott addresses the Caremark case in an intelligent and insightful way. ${ }^{32}$ This topic leads her to suggest a modest and interesting adaption. She suggests that if senior management is involved (not in a financially self-interested way, but in a hands-on manner) in a transaction that violates rules and causes loss, then, in a later shareholder action seeking to recover corporate losses from the officer himself, the officer should have the burden to establish the elements of the business judgment rule. ${ }^{33}$ The rationale for this innovation is that it creates an enhanced but not draconian incentive on the part of senior management to monitor compliance with law. In that event, I assume that such a director would be required to show that he had made a good faith effort to be reasonably informed with respect to the matter and that he exercised judgment in a good faith effort to advance the corporation's interests. Therefore, as Professor D eM ott notes, a lot goes into one's concept of good faith. ${ }^{34}$

The concept of good faith, which in my understanding of the fiduciary duties of corporate directors is the central dominating idea of the field, is of course problematic. How can courts tell when good faith is present, and do we really want this area of the law governed essentially by the presence or absence of a state of mind? It is particularly difficult when legal compliance is at issue and the corporation may financially benefit from a violation. What does good faith require of a director in that context? Surely, you might think that corporation law cannot encourage frank violations of the law by permitting indemnification when laws are knowingly and intentionally violated, even if the officer who authorized the acts constituting the violation calculated that the benefit to the corporation from the violation exceeded the expected value of the penalty plus all costs associated with the violation. But what about our earlier hypothetical where a responsible calculation was made of the air pollution rules and their penalties in picking a set of production inputs that risked some level of occasional violation? When a violation occurs and the government levies a fine and the shareholders sue to try to recover it from the officer who supervised and approved the decision, should she not be able to establish good faith for business judgment purposes? Meaning, should she not be able to demonstrate that as between herself and the corporation there can be no liability for the loss, so long as she authorized the acts constituting the violation in a good faith attempt to rationally calculate the costs and benefits of certain compliance and alternative courses of action that involved degrees of risk of violation of the legal command. If your answer is yes to this question, as I think mine would be, then you might evaluate Professor D eM ott's suggestion positively, as I do.

\footnotetext{
32. See id. at $40-43,52-53,59-61$.

33. See id. at 63-65.

34. Seeid.
} 
Were Professor D eM ott's suggestion adopted, I doubt that it would have an impact on the outcome of cases, but it very well might have a substantial signaling and risk-enhancing effect on the way directors behave. Whether you think that is good policy or not again depends on whether you prefer corporations to run little or no risk of rule violation (complete deterrence) or whether you suppose that the general good would more likely be advanced if managers are permitted to make some judgments about reasonable compliance (fitted or optimal deterrence). I suppose that, in all events, a rational system would have the corporation pay an appropriate fine if it happens that its production processes violate a rule, but would impose no derivative liability on directors so long as they had no direct financial interest and made an informed, good faith judgment concerning an appropriate compliance effort.

IV

\section{CONCLUSION}

It is this dichotomy between complete deterrence and optimal deterrence that is a core concern of policy. H ow close to complete deterrence or how close to optimal deterrence will our policy in any area get us? If we are at all concerned about over-deterrence, we must be very sensitive to the impact that a rule making corporate officers personally liable for wrong decisions would have. Of course intuitively many of us will not be especially concerned about over-deterrence. M any of us tend to be more concerned about what we seeviolations-than what we cannot see-opportunity losses. Thus, politically or socially, we tend to be concerned about deterrence, not over-deterrence. But our welfare as a people requires us to be concerned about opportunity losses that enforcement of legal rules can impose. The Delaware corporation law, correctly understood, powerfully protects that interest by its implicit concern with over-deterrence. That is what the business judgment rule is all about. 